\title{
BMJ Open Comparison of success criteria based on long-term symptoms and new-onset hypertension in mandibular advancement device treatment for obstructive sleep apnoea: observational cohort study
}

Jee Hye Wee, ${ }^{1}$ Jae Hyun Lim, ${ }^{2}$ January E Gelera, ${ }^{2,3}$ Chae-Seo Rhee, ${ }^{2}$ Jeong-Whun $\mathrm{Kim}^{2}$

To cite: Wee JH, Lim JH, Gelera JE, et al. Comparison of success criteria based on long-term symptoms and new-onset hypertension in mandibular advancement device treatment for obstructive sleep apnoea: observational cohort study. BMJ Open 2018;8:e021644. doi:10.1136/ bmjopen-2018-021644

- Prepublication history for this paper is available online. To view these files, please visit the journal online (http://dx.doi. org/10.1136/bmjopen-2018021644).

Received 10 January 2018 Revised 16 March 2018 Accepted 23 March 2018

(A) Check for updates

${ }^{1}$ Department of

Otorhinolaryngology-Head and

Neck Surgery, Bundang Jesaeng General Hospital, Daejin Medical Center, Seongnam, Republic of

Korea

${ }^{2}$ Department of

Otorhinolaryngology-Head and Neck Surgery, Seoul National University Bundang Hospital, Seoul National University College of Medicine, Seoul, Republic of Korea

${ }^{3}$ Department of

Otorhinolaryngology-Head and

Neck Surgery, University of

Santo Tomas Hospital, Manila, Philippines

Correspondence to Dr Jeong-Whun Kim; kimemail@snu.ac.kr

\section{ABSTRACT}

Objective To identify adequate criteria to determine the success or failure of mandibular advancement device (MAD) treatment for obstructive sleep apnoea (OSA) based on long-term symptoms and new-onset hypertension.

Design Observational cohort study.

Setting A tertiary care hospital setting in South Korea.

Participants Patients (age $>18$ years) who were diagnosed with OSA by a polysomnography (PSG) or Watch peripheral arterial tonometry (PAT), and who had been treated with MAD between January 2007 and December 2014 were enrolled.

Primary and secondary outcome measures Patients underwent PSG or Watch PAT twice; before and 3 months after the application of MAD. The patients were categorised into success and failure groups using seven different criteria. MAD compliance, witnessed apnoea and snoring, Epworth Sleepiness Scale score and occurrence of new-onset hypertension were surveyed via telephonic interview to determine the criteria that could identify success and failure of MAD.

Results A total of 97 patients were included. The mean follow-up duration was 60.5 months, and the mean apnoea-hypopnoea index (AHI) was 35.5/hour. Two of the seven criteria could significantly differentiate the success and failure groups based on long-term symptoms, including (1) $A H \mathrm{~K}<10 /$ hour with MAD and (2) $A H \mathrm{~K}<10$ / hour and $\mathrm{AHI}$ reduction of $>50 \%$ with MAD. Kaplan-Meier survival analysis showed that one criterion of $A H \mathrm{C}<15 /$ hour with MAD could differentiate the success and failure groups based on new-onset hypertension $(p=0.035)$. The receiver operating characteristic curve analysis indicated that the cut-off AHI for new-onset hypertension was 16.8/ hour $(71.4 \%$ sensitivity and $75.0 \%$ specificity).

Conclusion Our long-term follow-up survey for symptoms and new-onset hypertension suggested that some of the polysomnographic success criteria, that is, $A H I<10 /$ hour with $M A D, A H I<10 /$ hour and $A H I$ reduction of $>50 \%$ with $M A D$ and $A H I<15 /$ hour with MAD may be useful in distinguishing the success group from failure one. Further
Strengths and limitations of this study

- Strength of this study is that this is an observational cohort study to identify the optimal polysomnographic success criteria for mandibular advancement device treatment based on long-term subjective symptom changes or occurrence of new-onset hypertension.

- This study was limited in its telephonic interview-based study design.

- Diagnosis of hypertension was estimated based on a physician-diagnosed disease.

- Potential interviewer bias and respondent's recall bias may exist.

prospective longitudinal studies are warranted to validate these criteria.

\section{INTRODUCTION}

Obstructive sleep apnoea (OSA) is associated with many chronic diseases ${ }^{1}$ such as cardiovascular diseases, ${ }^{2}$ cerebrovascular diseases, ${ }^{3}$ metabolic syndrome ${ }^{4}$ and neurocognitive dysfunction. ${ }^{5}$ Furthermore, it may be a risk factor for the future development of hypertension. ${ }^{6}$ A short-term randomised controlled trial showed that continuous positive airway pressure (CPAP) treatment for OSA reduces cardiovascular morbidity. ${ }^{8}$ Therefore, it is important to focus on effective treatments for OSA to reduce its associated comorbidities.

The mandibular advancement device (MAD) is generally indicated for use in patients with mild-to-moderate OSA. ${ }^{9}$ However, MAD treatment is not always inferior to CPAP therapy and has been reported to show better compliance than CPAP. ${ }^{10} 11$ MAD 
treatment has shown beneficial effects on the number of obstructive breathing events, arterial oxygen saturation levels and arousal frequency. ${ }^{12}$ Furthermore, meta-analysis of several observational and randomised controlled trials showed that MAD reduces blood pressure in patients with OSA. ${ }^{1314}$ Although MAD is frequently prescribed by sleep specialists due to its efficacy, there is no validated standard criterion for determining the success or failure of this treatment for OSA based on long-term subjective symptomatic improvement or occurrence of medical comorbidities. Theoretically, an apnoea-hypopnoea index $(\mathrm{AHI})<15 /$ hour or $\mathrm{AHI}<5 /$ hour without symptoms such as witnessed snoring, apnoea, and daytime sleepiness are required for treatment success. However, these polysomnography (PSG)-based definitions of success do not always agree with subjective improvement experienced by patients. Furthermore, the literature provides various criteria for defining treatment success. One recent study reported that the success rate of OSA treatment with MAD can vary remarkably according to the success criteria. ${ }^{15}$ However, success or failure cannot be defined by PSG findings alone. A long-term observation of symptom improvement or occurrence of complications is necessary to identify the relationship between success/ failure and PSG findings with MAD.

To the best of our knowledge, no long-term follow-up study based on subjective symptom changes or occurrence of new-onset hypertension has thus far identified the optimal PSG success criteria for MAD treatment. Therefore, in the present study, we aimed to determine adequate success criteria for MAD treatment of OSA on the basis of long-term symptoms and occurrence of new-onset hypertension.

\section{METHODS}

\section{Patients}

This observational cohort study included consecutive patients (age $>18$ years) who were diagnosed with OSA (AHI $\geq 5$ /hour and symptoms of snoring, fragmented sleep, witnessed apnoea or daytime sleepiness) by an attended, full-night, in-laboratory PSG or Watch peripheral arterial tonometry (PAT), and who had been treated with MAD at our sleep clinic between January 2007 and December 2014. The MAD was designed to hold the mandible fixed at $60 \%$ of the maximum protrusion. All the patients were regularly followed up to evaluate any dental or temporomandibular joint problems and to adjust the advancement length. Data regarding demographic parameters, including body mass index (BMI), daytime sleepiness (by the Epworth Sleepiness Scale (ESS)), medical diseases and current medication use were collected. Blood pressure was measured at the start of MAD treatment. Patients underwent PSG or Watch PAT twice; before and 3 months after the application of MAD.

Patients with the following conditions were excluded for MAD treatment: central sleep apnoea; regular use of sedatives or narcotics; pre-existing pulmonary or

\begin{tabular}{|c|c|}
\hline Criteria & Definition of success \\
\hline 1 & $\mathrm{AHI}<10 /$ hour with $\mathrm{MAD}$ \\
\hline 2 & $A H I<15 /$ hour with MAD \\
\hline 3 & AHI $<20 /$ hour with MAD \\
\hline 4 & $\mathrm{AHI}<10 /$ hour and $\mathrm{AHI}$ reduction of $>50 \%$ with $\mathrm{MAD}$ \\
\hline 5 & $\mathrm{AHI}<15 /$ hour and $\mathrm{AHI}$ reduction of $>50 \%$ with $\mathrm{MAD}$ \\
\hline 6 & $\mathrm{AHI}<20 /$ hour and $\mathrm{AHI}$ reduction of $>50 \%$ with $\mathrm{MAD}$ \\
\hline 7 & $\mathrm{AHI}$ reduction of $>50 \%$ with $\mathrm{MAD}$ \\
\hline
\end{tabular}

AHI, apnoea-hypopnoea index; MAD, mandibular advancement device.

psychiatric diseases; and any contraindication for MAD such as poor teeth, periodontitis and temporomandibular joint disorders. Patients who were not available for telephone interviews or have missing data for any of the variables were excluded from the study.

\section{Criteria of treatment success}

The following six criteria for OSA treatment success which have been used in the literature were analysed, as described in our previous study ${ }^{16}$ : AHI $<10 /$ hour with $\mathrm{MAD}$; $\mathrm{AHI}<20 /$ hour with $\mathrm{MAD}$; $\mathrm{AHI}<10 /$ hour and $\mathrm{AHI}$ reduction of $>50 \%$ with $\mathrm{MAD}$; $\mathrm{AHI}<15 /$ hour and $\mathrm{AHI}$ reduction of $>50 \%$ with $\mathrm{MAD}$; $\mathrm{AHI}<20 /$ hour and $\mathrm{AHI}$ reduction of $>50 \%$ with $\mathrm{MAD}$; and $\mathrm{AHI}$ reduction of $>50 \%$ with MAD. We added another criterion of $\mathrm{AHI}<15 /$ hour with MAD, which is the cut-off AHI to differentiate mild from moderate OSA. Thereafter, patients were categorised into the success and failure groups based on each of the seven criteria (table 1 ).

\section{Collection of follow-up data}

Follow-up data were obtained via telephonic interviews using a specially designed questionnaire. Telephonic interview was performed at least twice for each patient with the same questionnaires to confirm their answers. For data on MAD compliance, time of use per night and number of nights per week were assessed. Good compliance was defined as the use of MAD $>4$ hour/ night for $\geq 5$ days/week. ${ }^{17}$ Witnessed apnoea and snoring were asked to score on a scale from 0 (no symptom) to 10 (very bad), and the ESS score was used to assess the likelihood of falling asleep in eight different situations. In addition, occurrence of physician-diagnosed new-onset hypertension and antihypertensive medications since commencement of MAD treatment was assessed based on longitudinal review of our electronic medical system and telephonic interview.

\section{Statistical analysis}

All statistical analyses were performed using SPSS V.18. Continuous variables are expressed as the mean $\pm \mathrm{SD}$, and categorical variables are expressed as proportions. Paired t-tests were used to compare the sleep-related 


\begin{tabular}{|c|c|}
\hline Characteristics & $\begin{array}{l}\text { Measure at } \\
\text { baseline }\end{array}$ \\
\hline \multicolumn{2}{|l|}{ Sex, n (\%) } \\
\hline Male & $77(79.4)$ \\
\hline Female & $20(20.6)$ \\
\hline Age, years, mean (SD) & $50.8(9.9)$ \\
\hline BMI, kg/m², mean (SD) & $25.8(2.8)$ \\
\hline Follow-up duration, months, mean (SD) & $60.5(26.6)$ \\
\hline \multicolumn{2}{|l|}{ Compliance, n (\%) } \\
\hline Good & $20(20.6)$ \\
\hline Poor & $77(79.4)$ \\
\hline $\begin{array}{l}\text { Apnoea-hypopnoea index, /hour, mean } \\
\text { (SD) }\end{array}$ & $35.5(19.8)$ \\
\hline \multicolumn{2}{|l|}{ Severity categories, n (\%) } \\
\hline None (0-4.9 events/hour) & $0(0.0)$ \\
\hline Mild (5-14.9 events/hour) & $11(11.3)$ \\
\hline Moderate (15-29.9 events/hour) & $38(39.2)$ \\
\hline Severe ( $\geq 30$ events/hour) & $48(49.5)$ \\
\hline \multicolumn{2}{|l|}{ Positional dependency, n (\%) } \\
\hline Position-dependent OSA & $90(92.8)$ \\
\hline Position-non-dependent OSA & $7(7.2)$ \\
\hline
\end{tabular}

BMI, body mass index; OSA, obstructive sleep apnoea.

parameters before and after MAD application in all patients. Unpaired t-tests were used to examine the differences in witnessed apnoea, snoring and ESS score between the success and failure groups. A repeated-measure analysis of variance (ANOVA) was used to assess changes in variables from pretreatment to post-treatment between groups. Survival analysis was used to compare the time elapsed from MAD prescription to newly diagnosed hypertension between groups. Survival analysis was conducted using Kaplan-Meier survival curves. With regard to the post-treatment AHI value as a parameter for differentiating patients with new-onset hypertension from healthy subjects, sensitivity and specificity values for optimal cut-off were calculated using the receiver operating characteristic (ROC) curve. A p value $<0.05$ was considered statistically significant.

\section{Patient and public involvement}

Patients were not involved in setting the research question and in the design of the study. We introduced the purpose of this research to the patients. Informed consents were sought from all the participants. All the participants completed this survey on the voluntary basis. Small gifts were given to the participants who completed this telephonic interview. No patient was asked for advice on interpretation or writing up of results. The results of the research will not be disseminated to the patients.

\section{RESULTS}

Out of 214 MAD-treated patients who underwent the follow-up sleep study, 107 were not available for telephone interviews because of phone number change or rejection or had missing data. Thus, a total of 97 patients (77 $(79.4 \%)$ men and 20 (20.6\%) women) were enrolled, and their characteristics are presented in table 2. The baseline age, BMI and AHI was 50.8 \pm 9.9 years (range, $19-68$ years), $25.8 \pm 2.8 \mathrm{~kg} / \mathrm{m}^{2}$ and $35.5 \pm 19.8 /$ hour, respectively. According to Cartwright's criteria, ${ }^{18} 90$ patients had position-dependent OSA and 7 patients had position-independent OSA.

\section{Short-term PSG follow-up with MAD}

Table 3 summarises the sleep-related parameters before and 3 months after application of the MAD. After treatment, there was significant improvement in AHI $(p<0.001)$, apnoea index $(p<0.001)$, supine AHI $(\mathrm{p}<0.001)$, lateral AHI $(\mathrm{p}=0.004)$, lowest $\mathrm{O}_{2}$ saturation $(\mathrm{p}<0.001)$, oxygen desaturation index $(\mathrm{p}<0.001)$ and the percentage of sleep time with snoring $(p<0.001)$.

\section{Long-term symptomatic changes}

The mean follow-up duration was $60.5 \pm 26.6$ months (range, 8-107 months). Table 4 shows the changes in witnessed apnoea, snoring and ESS after MAD treatment in the success and failure groups according to the seven criteria. The highest rate of treatment success was $74.2 \%$ (72/97 patients) when using criterion 3 (AHI $<20 /$ hour with MAD) and lowest at $45.4 \%$ (45/97 patients) when using criterion 4 (AHI $<10 /$ hour and AHI reduction of $>50 \%$ with $\mathrm{MAD}$ ).

Repeated-measure ANOVA analyses adjusted for age, sex, BMI and compliance identified adequate criteria in determining the success or failure of MAD based on longterm symptom improvement. With criteria $2(\mathrm{AHI}<15 /$ hour with MAD), 3 (AHI $<20 /$ hour with $\mathrm{MAD}$ ) and 5 (AHI $<15$ /hour and AHI reduction of $>50 \%$ with $\mathrm{MAD})$, there was no significant difference in the improvement of symptoms between the success and failure groups.

Table 3 Changes in the sleep-related parameters before and after treatment with a mandibular advancement device

\begin{tabular}{llll}
\hline $\begin{array}{l}\text { Polysomnographic } \\
\text { index, mean (SD) }\end{array}$ & Baseline & $\begin{array}{l}\text { After } \\
\text { treatment }\end{array}$ & P values* \\
\hline AHI (/hour) & $35.5(19.8)$ & $15.2(13.7)$ & $<0.001$ \\
\hline Apnoea index (/hour) & $26.8(20.1)$ & $7.7(10.8)$ & $<0.001$ \\
Supine AHI (/hour) & $50.1(23.5)$ & $20.1(19.8)$ & $<0.001$ \\
Lateral AHI (/hour) & $8.1(15.1)$ & $3.5(8.6)$ & 0.004 \\
$\begin{array}{l}\text { Lowest O } \\
\text { (\%) saturation }\end{array}$ & $78.0(10.8)$ & $83.3(7.6)$ & $<0.001$ \\
$\begin{array}{l}\text { Oxygen desaturation } \\
\text { index (/hour) }\end{array}$ & $28.7(19.6)$ & $11.4(12.3)$ & $<0.001$ \\
Snoring (\%) & $36.1(18.1)$ & $27.4(21.6)$ & $<0.001$ \\
\hline
\end{tabular}

${ }^{*} \mathrm{P}$ value for the paired t-test.

AHI, apnoea-hypopnoea index. 







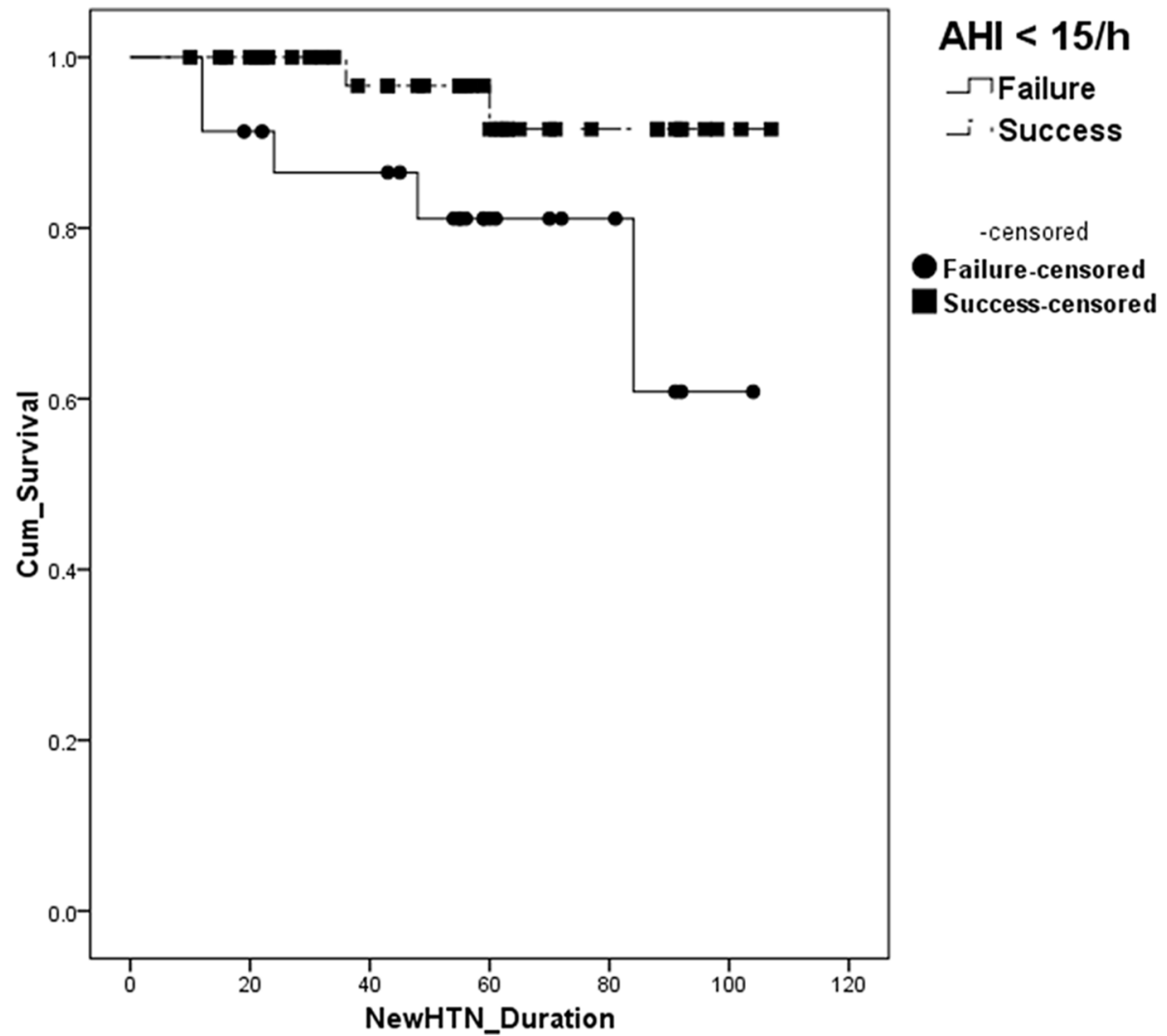

Figure 1 Kaplan-Meier survival curves for new-onset of hypertension (HTN) in success and failure groups. AHI, apnoeahypopnoea index.

With criteria 6 (AHI reduction of $>50 \%$ with MAD) and 7 $(\mathrm{AHI}<20$ /hour and AHI reduction of $>50 \%$ with $\mathrm{MAD})$, only ESS improved to a larger extent than that in the success group. In contrast, there was a significantly larger improvement in the witnessed apnoea, snoring and ESS from pretreatment to post-treatment in the success group compared with the failure group when using criteria 1 $(\mathrm{AHI}<10 /$ hour with $\mathrm{MAD})$ and $4(\mathrm{AHI}<10 /$ hour and AHI reduction of $>50 \%$ with MAD).

\section{Survival analysis for new-onset hypertension}

Among the 97 patients, $34(35.1 \%)$ had hypertension before treatment and 7 patients were newly diagnosed with hypertension during the follow-up and all of the 7 patients showed poor compliance. Kaplan-Meier survival analyses were performed for all the seven success criteria and the analysis showed that only criterion 2 (AHI $<15$ / hour with MAD) could significantly differentiate between success and failure on the basis of new-onset hypertension ( $\mathrm{p}=0.045)$ (figure 1).

\section{ROC curve analysis for new-onset hypertension}

For assuming post-treatment AHI value as a parameter differentiating patient with new-onset hypertension from healthy ones, the ROC curve analysis indicated that the cut-off AHI was 16.8/hour, with an area under the curve of $0.704(\mathrm{p}=0.080)$, a sensitivity of $71.4 \%$ and a specificity of $75.0 \%$ (figure 2 ).

\section{DISCUSSION}

To our knowledge, this is the first study to identify adequate criteria to determine the success or failure of MAD as a treatment based on long-term symptom improvement and occurrence of new-onset hypertension in OSA. The most commonly used criterion for surgical success for OSA is postoperative $\mathrm{AHI}<20$ /hour and $\mathrm{AHI}$ reduction of $>50 \% .{ }^{19} \mathrm{CPAP}$ therapy is a standard treatment of OSA and considered to be successful if the AHI reduces to $<5$ /hour with CPAP. ${ }^{20}$ Although MAD is one of the treatment options of OSA, there is no standardised criterion to define successful outcome of MAD treatment. Although one study emphasised the need to establish a uniform definition of treatment success of OSA by using the MAD, they did not suggest an adequate criterion. ${ }^{15}$

Generally, the effectiveness of treatments for OSA is reported as change in AHI. However, it is unclear whether symptoms or comorbidities persist when AHI is improved by such treatment. Recent evidence indicates that there is no correlation between $\mathrm{AHI}$ and clinical outcomes ${ }^{21-23}$ and emphasises subjective sleepiness, snoring, quality of life and prevention of deleterious effects on comorbidities. Furthermore, several studies have demonstrated a discrepancy between statistically significant outcomes and clinically relevant outcomes. One review ${ }^{24}$ highlighted the importance of 'highly effective treatment' over 'subtherapeutic treatment' as a necessity for improved health outcomes in OSA. Thus, we focused on the long-term 


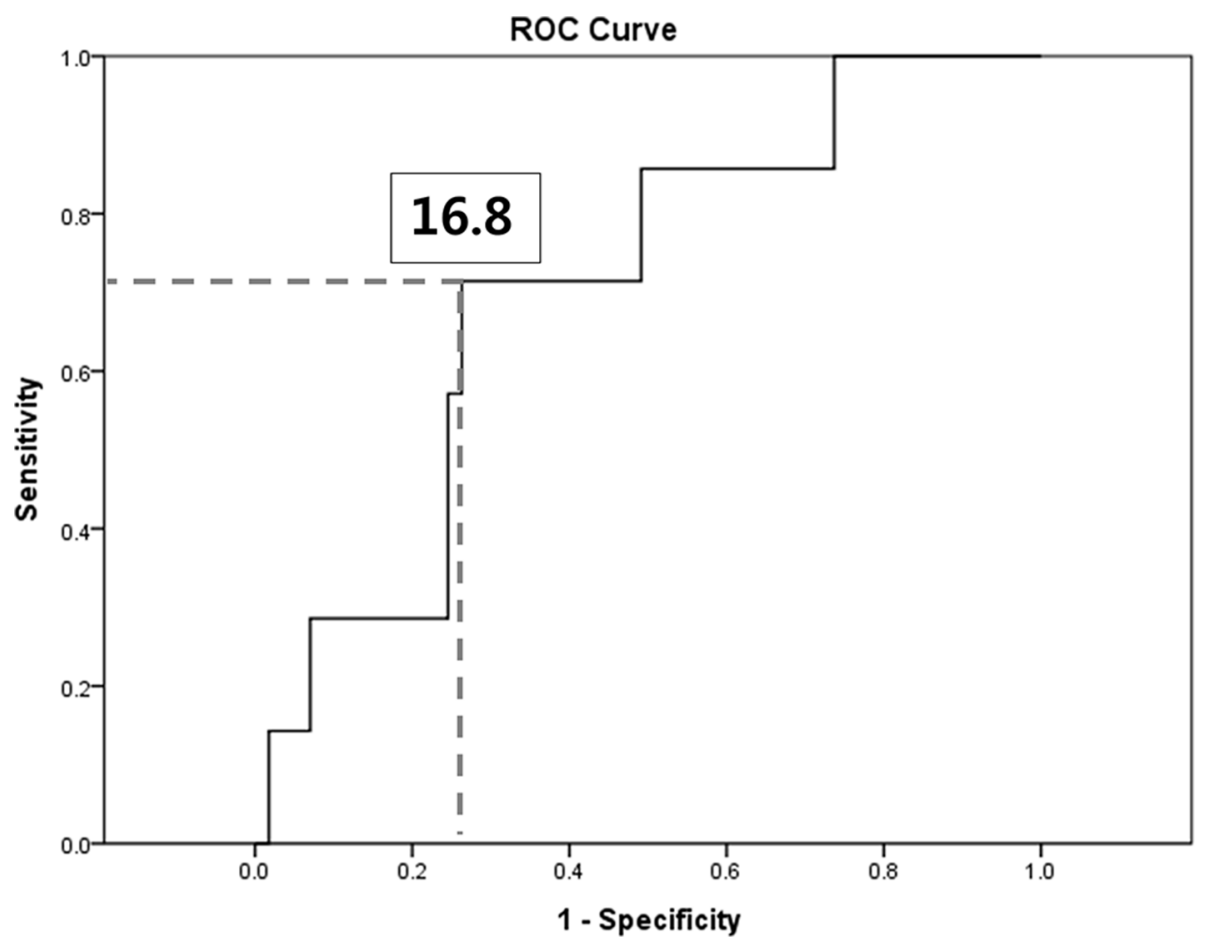

Figure 2 Receiver operating characteristic (ROC) curve of apnoea-hypopnoea index with mandibular advancement device for new-onset hypertension.

sleep-related symptomatic changes and occurrence of new-onset hypertension.

We found that two success criteria based on the AHI change with $\mathrm{MAD}-\mathrm{AHI}<10 /$ hour with $\mathrm{MAD}$ and AHI $<10$ /hour and AHI reduction of $>50 \%$ with MADcould differentiate between success and failure on the basis of all three long-term OSA-related symptoms such as witnessed apnoea, snoring and daytime sleepiness. Given that PSG-based assessment of treatment response may not always agree with subjective improvement experienced by patients, these criteria may be helpful when sleep doctors interpret subjective symptomatic changes after application of MAD.

This study also showed that the criterion of $\mathrm{AHI}<15$ / hour with MAD differentiated success from failure on the basis of new-onset hypertension. OSA is known to be an independent risk factor for the development of hypertension. ${ }^{625}$ In contrast, in a sleep heart health cohort study, sleep-disordered breathing was a not a significant independent predictor of incident hypertension after adjusting for BMI. However, in a subgroup analysis, sleep-disordered breathing predicted future hypertension among women and less obese persons $\left(\mathrm{BMI} \leq 27.3 \mathrm{~kg} / \mathrm{m}^{2}\right){ }^{27}$ In our study, all patients were Asians, who are generally less obese than the Western population. A meta-analysis showed that MAD treatment for OSA improves blood pressure control and suggested that blood pressure reduction may portend significant risk reduction for prevalent comorbidities such as hypertension. ${ }^{13} \mathrm{~A}$ recent study reported that the effects of an adjustable MAD were not significantly different to CPAP in terms of 24-hour mean ambulatory blood pressure, daytime sleepiness and disease-specific and general quality of life. ${ }^{11}$ Furthermore, the latest guideline for oral appliance use in OSA by the American Academy of Sleep Medicine (AASM) and American Academy of Dental Sleep Medicine (AADSM) shows a modest impact on reducing blood pressure. ${ }^{12}$

In the current study, nearly half of the patients had severe OSA. The guideline of the AASM on OSA treatment suggests that MAD should primarily be used in patients with mild-to-moderate OSA. ${ }^{10}$ However, in a previous study, patients with severe OSA had comparable successful outcomes to those with moderate OSA who received MAD treatment. ${ }^{28}$ In particular, in the group with moderate-to-severe OSA, patients with position-dependent OSA had better treatment outcomes with an MAD than patients with position-independent OSA. ${ }^{29}$ In the present study, most patients $(92.8 \%)$ had position-dependent OSA. In addition, recent meta-analysis by AASM/AADSM showed significant efficacy across all level of OSA severity in adult patients using oral appliance. ${ }^{12}$

However, our study was limited in its telephonic interview-based study design. There was a period between the follow-up sleep apnoea/hypopnoea test and the telephonic interview. Potential interviewer bias and respondent's recall bias may exist. The efficacy of the MAD may be changed or there may be some other changes in bodyweight or compliance that may influence the symptomatic benefit. Therefore, we adjusted the effects for the age, sex, BMI and compliance in the statistical analyses. In this study, diagnosis of hypertension was estimated based on a physician-diagnosed disease. However, even in sleep heart health study, they reported the association between sleep-disordered breathing and self-reported cardiovascular disease. $^{7}$ In 
addition, subjective compliance was assessed using self-report. Objective compliance can be measured when using MAD that embedded temperature-sensitive microsensor. However, a previous study has reported a high agreement between self-reported and objectively measured compliance. $^{30}$ Considering that most previous studies have focused on simple comparisons between AHI without or with MAD, this study may have another clinical implication as it highlights the relationships between the AHI changes with $\mathrm{MAD}$ and long-term symptom improvement or occurrence of one of medical comorbidities. Patients underwent PSG or Watch PAT. Although the same sleep studies were performed for pre treatment and post treatment in terms of each patient, there is still a limitation in the reliability of using Watch PAT. A previous study showed that Watch PAT has a limited value in detecting mild OSA while it is useful in detecting moderate to severe OSA. ${ }^{31}$

In conclusion, the present study demonstrated that $\mathrm{AHI}<10 /$ hour with $\mathrm{MAD}$ or $\mathrm{AHI}<10 /$ hour and AHI reduction of $>50 \%$ with MAD may be useful as criteria to distinguish successful patients from unsuccessful ones on the basis of long-term symptom improvement. In addition, $\mathrm{AHI}<15 /$ hour with MAD may be a criterion to differentiate between success and failure groups on the basis of new-onset hypertension. Future prospective studies are warranted to validate our proposed success criteria.

Acknowledgements The authors thank all members of research team for the patient advisers and for the assistance in data collection.

Contributors JHW, C-SR and J-WK conceived the study design. JHL and JEG coordinated the study. JHW and JHL completed data collection and made the statistical analysis. JHW and J-WK conducted interpretation of results and drafted the manuscript. CSR and J-WK revised the manuscript for important intellectual content. All authors read and approved the final manuscript.

Funding This study was partly supported by the research Fund from the Seoul National University Bundang Hospital (Grant No. 02-2015-035) and the Bio \& Medical Technology Development Program of the National Research Foundation (NRF) funded by the Ministry of Science and ICT (NRF-2015M3A9D7066972).

Disclaimer The funding organisations had no role in the design and conduct of the study; in the collection, management, analysis and interpretation of the data; in the preparation, review or approval of the manuscript; and in the decision to submit the manuscript for publication.

Competing interests None declared.

Patient consent Obtained.

Ethics approval This study was approved by the Seoul National University Bundang Hospital Institutional Review Board, and the study was conducted according to the principles expressed in the Declaration of Helsinki.

Provenance and peer review Not commissioned; externally peer reviewed. Data sharing statement № additional data available.

Open Access This is an Open Access article distributed in accordance with the Creative Commons Attribution Non Commercial (CC BY-NC 4.0) license, which permits others to distribute, remix, adapt, build upon this work non-commercially, and license their derivative works on different terms, provided the original work is properly cited and the use is non-commercial. See: http://creativecommons.org/ licenses/by-nc/4.0/

(C) Article author(s) (or their employer(s) unless otherwise stated in the text of the article) 2018. All rights reserved. No commercial use is permitted unless otherwise expressly granted.

\section{REFERENCES}

1. Mokhlesi B, Ham SA, Gozal D. The effect of sex and age on the comorbidity burden of OSA: an observational analysis from a large nationwide US health claims database. Eur Respir J 2016;47:1162-9.

2. Somers VK, White DP, Amin R, et al. Sleep apnea and cardiovascular disease: an American Heart Association/american College Of Cardiology Foundation Scientific Statement from the American Heart Association Council for High Blood Pressure Research Professional Education Committee, Council on Clinical Cardiology, Stroke Council, and Council On Cardiovascular Nursing. In collaboration with the National Heart, Lung, and Blood Institute National Center on Sleep Disorders Research (National Institutes of Health). Circulation 2008;118:1080-111.

3. Xie W, Zheng F, Song X. Obstructive sleep apnea and serious adverse outcomes in patients with cardiovascular or cerebrovascular disease: a PRISMA-compliant systematic review and meta-analysis. Medicine 2014;93:e336.

4. Korcarz CE, Stein JH, Peppard PE, et al. Combined effects of sleep disordered breathing and metabolic syndrome on endothelial function: the Wisconsin Sleep Cohort study. Sleep 2014;37:1707-13.

5. Zhou J, Camacho M, Tang X, et al. A review of neurocognitive function and obstructive sleep apnea with or without daytime sleepiness. Sleep Med 2016;23:99-108.

6. Peppard PE, Young T, Palta M, et al. Prospective study of the association between sleep-disordered breathing and hypertension. $N$ Engl J Med 2000;342:1378-84.

7. Shahar E, Whitney CW, Redline S, et al. Sleep-disordered breathing and cardiovascular disease: cross-sectional results of the Sleep Heart Health Study. Am J Respir Crit Care Med 2001;163:19-25.

8. Becker HF, Jerrentrup A, Ploch T, et al. Effect of nasal continuous positive airway pressure treatment on blood pressure in patients with obstructive sleep apnea. Circulation 2003;107:68-73.

9. Epstein LJ, Kristo D, Strollo PJ, et al. Clinical guideline for the evaluation, management and long-term care of obstructive sleep apnea in adults. J Clin Sleep Med 2009;5:263-76.

10. Almeida FR, Henrich N, Marra C, et al. Patient preferences and experiences of CPAP and oral appliances for the treatment of obstructive sleep apnea: a qualitative analysis. Sleep Breath 2013;17:659-66.

11. Phillips CL, Grunstein RR, Darendeliler MA, et al. Health outcomes of continuous positive airway pressure versus oral appliance treatment for obstructive sleep apnea: a randomized controlled trial. $A m \mathrm{~J}$ Respir Crit Care Med 2013;187:879-87.

12. Ramar K, Dort LC, Katz SG, et al. Clinical practice guideline for the treatment of obstructive sleep apnea and snoring with oral appliance therapy: an update for 2015. J Clin Sleep Med 2015;11:773-827.

13. Iftikhar IH, Hays ER, Iverson MA, et al. Effect of oral appliances on blood pressure in obstructive sleep apnea: a systematic review and meta-analysis. J Clin Sleep Med 2013;9:165-74.

14. Bratton DJ, Gaisl T, Wons AM, et al. CPAP vs Mandibular advancement devices and blood pressure in patients with obstructive sleep apnea: a systematic review and meta-analysis. JAMA 2015;314:2280-93.

15. Fukuda T, Tsuiki S, Kobayashi M, et al. Selection of response criteria affects the success rate of oral appliance treatment for obstructive sleep apnea. Sleep Med 2014;15:367-70.

16. Lee WH, Hong SN, Kim HJ, et al. A Comparison of different success definitions in non-continuous positive airway pressure treatment for obstructive sleep apnea using cardiopulmonary coupling. J Clin Sleep Med 2016;12:35-41.

17. Kribbs NB, Pack Al, Kline LR, et al. Objective measurement of patterns of nasal CPAP use by patients with obstructive sleep apnea. Am Rev Respir Dis 1993;147:887-95.

18. Cartwright RD. Effect of sleep position on sleep apnea severity. Sleep 1984;7:110-4.

19. Sher AE, Schechtman KB, Piccirillo JF. The efficacy of surgical modifications of the upper airway in adults with obstructive sleep apnea syndrome. Sleep 1996;19:156-77.

20. Ravesloot MJ, de Vries N. Reliable calculation of the efficacy of nonsurgical and surgical treatment of obstructive sleep apnea revisited. Sleep 2011;34:105-10.

21. Moyer CA, Sonnad SS, Garetz SL, et al. Quality of life in obstructive sleep apnea: a systematic review of the literature. Sleep Med 2001;2:477-91.

22. Thong JF, Pang KP. Clinical parameters in obstructive sleep apnea: are there any correlations? J Otolaryngol Head Neck Surg 2008;37:894-900.

23. Tam S, Woodson BT, Rotenberg B. Outcome measurements in obstructive sleep apnea: beyond the apnea-hypopnea index. Laryngoscope 2014;124:337-43. 
24. Elshaug AG, Moss JR, Southcott AM, et al. Redefining success in airway surgery for obstructive sleep apnea: a meta analysis and synthesis of the evidence. Sleep 2007;30:461-7.

25. Grote L, Ploch T, Heitmann J, et al. Sleep-related breathing disorder is an independent risk factor for systemic hypertension. Am J Respir Crit Care Med 1999;160:1875-82.

26. Lavie P, Herer P, Hoffstein V. Obstructive sleep apnoea syndrome as a risk factor for hypertension: population study. BMJ 2000;320:479-82.

27. O'Connor GT, Caffo B, Newman AB, et al. Prospective study of sleep-disordered breathing and hypertension: the Sleep Heart Health Study. Am J Respir Crit Care Med 2009;179:1159-64.
28. Lee $\mathrm{CH}, \mathrm{Mo} \mathrm{JH}$, Choi IJ, et al. The mandibular advancement device and patient selection in the treatment of obstructive sleep apnea. Arch Otolaryngol Head Neck Surg 2009;135:439-44.

29. Lee $\mathrm{CH}$, Jung HJ, Lee WH, et al. The effect of positional dependency on outcomes of treatment with a mandibular advancement device. Arch Otolaryngol Head Neck Surg 2012;138:479-83.

30. Dieltjens M, Braem MJ, Vroegop A, et al. Objectively measured vs self-reported compliance during oral appliance therapy for sleepdisordered breathing. Chest 2013;144:1495-502.

31. Yuceege M, Firat H, Demir A, et al. Reliability of the Watch-PAT 200 in detecting sleep apnea in highway bus drivers. $J$ Clin Sleep Med 2013;9:339-44. 